\title{
Functional characterization of wild-type and mutated pendrin (SLC26A4), the anion transporter involved in Pendred syndrome
}

\author{
Silvia Dossena ${ }^{1}$, Simona Rodighiero ${ }^{2}$, Valeria Vezzoli ${ }^{1,3}$, Charity Nofziger ${ }^{1}$, \\ Elisabetta Salvioni ${ }^{1,3}$, Marta Boccazzi ${ }^{1,3}$, Elisabeth Grabmayer $^{1}$, Guido Bottà ${ }^{3}$, \\ Giuliano Meyer ${ }^{3}$, Laura Fugazzola ${ }^{4,5}$, Paolo Beck-Peccoz ${ }^{4,5}$ and Markus PaulmichI ${ }^{1}$ \\ ${ }^{1}$ Institut of Pharmacology and Toxicology, Paracelsus Medical University, A-5020 Salzburg, Austria \\ ${ }^{2}$ CIMAINA, ${ }^{3}$ Department of Biomolecular Sciences and Biotechnology and ${ }^{4}$ Department of Medical Sciences, Università degli Studi di Milano, I-20133 Milan, Italy \\ ${ }^{5}$ Endocrine and Diabetes Unit, Fondazione Policlinico, IRCCS, I-20122 Milan, Italy
}

(Correspondence should be addressed to M Paulmichl; Email: markus.paulmichl@pmu.ac.at)

\begin{abstract}
Pendred syndrome (PS) is the most frequent form of genetically related syndromic hearing loss, and is associated with mutations of pendrin, encoded by the SLC26A4 gene. This protein localizes to the cellular membrane and permits the exchange of anions between the cytosol and extracellular space. In the inner ear, pendrin conditions the endolymph, allowing for the proper function of sensory cells. Understanding the relationship between the genotype and phenotype of pendrin mutations would aid clinicians to better serve PS patients-however, little is known. Here, we summarize the available data concerning SLC26A4 mutations and how they relate to transporter function. The main findings suggest that all the truncation mutations tested annihilate pendrin function, and that the addition or omission of proline, or the addition or omission of charged amino acids in the sequence of SLC26A4 result in a substantial to dramatic reduction in pendrin function.
\end{abstract}

Journal of Molecular Endocrinology (2009) 43, 93-103

\section{Pendrin function}

Pendrin is a member of the anion transporter family SLC26, which mediates, as shown in Fig. 1, the exchange of anions including $\mathrm{Cl}^{-}, \mathrm{HCO}_{3}^{-}, \mathrm{OH}^{-}, \mathrm{I}^{-}$, or formate (Mount \& Romero 2004), and is encoded by the SLC26A4 gene. As shown in Fig. 1, in thyrocytes, iodide and sodium are brought into the cells via the basolaterally located sodium-iodide symporter. Apically located pendrin (Royaux et al. 2000) seems to be responsible for the efflux of iodide into the follicular lumen (Yoshida et al. 2002, 2004, Gillam et al. 2004). In the kidney, pendrin is suspected to mediate $\mathrm{Cl}^{-} / \mathrm{HCO}_{3}^{-}$ exchange in the acid-base regulating $\beta$ - and non- $\alpha-$ non- $\beta$-intercalated cells (Royaux et al. 2001, Soleimani et al. 2001, Kim et al. 2002). A substantial body of work is supporting this concept (Wall 2005, Cantone et al. 2006, Soleimani \& Xu 2006, Grimaldi et al. 2007, Hughey \& Kleyman 2007, Sindic et al. 2007, Wall \& Pech 2008). Similarly, in the inner ear, pendrin is thought to mediate $\mathrm{Cl}^{-} / \mathrm{HCO}_{3}^{-}$exchange, and is therefore involved in the conditioning of endolymphatic fluid, presumably due to $\mathrm{HCO}_{3}^{-}$secretion (Wangemann et al. 2007). Malfunction of pendrin leads to Pendred syndrome (PS).

\section{Pendred syndrome: clinical aspects}

PS (OMIM\#274600) is an autosomal recessive disorder accounting for $4-10 \%$ of inherited hearing losses (Batsakis \& Nishiyama 1962, Fraser 1965, Illum et al. 1972, Reardon et al. 1997). It was first described in 1896 as the combination of deafness and goiter (Pendred 1896), but the precise phenotype has been detailed in recent years (Masmoudi et al. 2000, Campbell et al. 2001, Blons et al. 2004, Napiontek et al. 2004) and involves two organ systems: the ear, and the thyroid gland. It is unclear whether or not the kidney could be involved under certain circumstances as well.

DOI: 10.1677/JME-08-0175 Online version via http://www.endocrinology-journals.org 


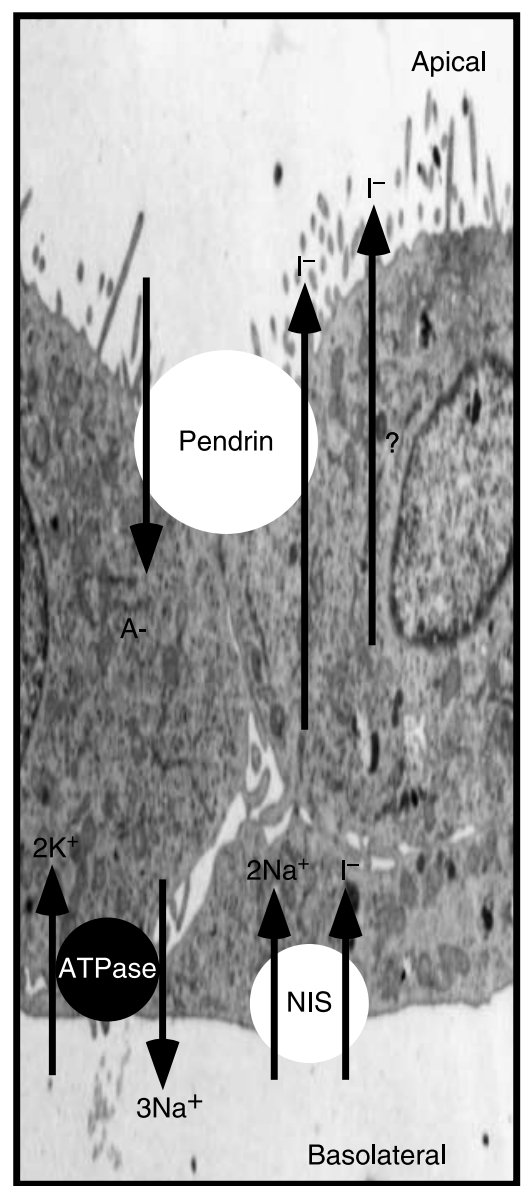

Figure 1 Cell model of the ion transport mechanisms in follicular cells of the thyroid gland. The sodium/potassium ATPase and the sodium/iodide symporter (NIS) are located on the basolateral side of follicular cells. At the apical side, pendrin is responsible for iodide transport into the follicules. However, an additional unknown iodide transporter may be expressed in the apical membrane.

\section{SLC26A4 mutations: the ear}

Under normal conditions, pendrin maintains the ionic composition of endolymph (Everett et al. 1999). It has therefore been hypothesized that impaired pendrin function i) promotes a progressive increase in endolymph volume followed by an enlargement of the membranous labyrinth and surrounding osseous structures, and ii) leads to degeneration of inner ear sensory cells (Everett et al. 2001). The resulting phenotype is a severe/profound sensorineural hearing loss (SNHL). The onset of deafness fluctuates in about $80 \%$ of cases. By contrast, the sudden development of the phenotype occurs only in a minority of patients. SNHL is invariably associated with malformations of the inner ear: enlarged vestibular aqueduct (EVA) is present in all patients with PS (Phelps et al. 1998), whereas Mondini malformations are less common
(Yang et al. 2005). These abnormalities can be detected in PS patients by computed tomography or nuclearmagnetic resonance of the petrous part of the temporal bone (Fig. 2).

\section{SLC26A4 mutations: the thyroid}

Impaired pendrin function at the thyroid level can result in goiter, defects in iodide organification, and hypothyroidism (Fugazzola et al. 2001, Grimaldi et al. 2007, Kopp et al. 2008). Surprisingly, the thyroid symptoms are highly variable. Indeed, goiter is not a constant feature and can range from a slight increase in thyroid size to a large multinodular goiter. Perchlorate tests have shown that the organification defect is only partial (Fugazzola et al. 2000), indicating the existence of another mechanism underlying the transfer of iodine from the cytoplasm to the colloid (Fig. 1), such as ion channels (Golstein et al. 1992, Yoshida et al. 1999). Accordingly, most patients are euthyroid or subclinical hypothyroid, depending on the level of iodine intake.

\section{SLC26A4 mutations: the kidney}

As far as the kidney is concerned, a decrease in pendrin function is not associated with disturbances in renal function. In particular, the regulation of electrolytes and acid-base balance remains normal despite the critical role of pendrin in bicarbonate secretion (Royaux et al. 2001). Indeed, when studied under basal conditions, no renal abnormalities have been reported in either PS patients or $P d s$-knockout animals. It is assumed that in the kidney, pendrin-dependent ion transport is safeguarded by redundant mechanisms, which most likely attenuate the change in intracellular and systemic $\mathrm{pH}$ expected to result from pendrin impairment (Kim et al. 2005). However, differences become apparent under conditions wherein the transporter is stimulated.
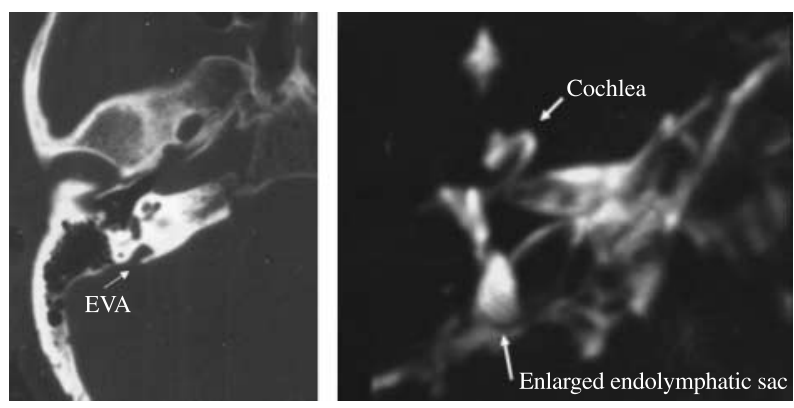

Figure 2 Enlarged vestibular aqueduct (EVA) and enlarged endolymphatic sac in PS patients. Computed tomographic (CT)-image (left), and a magnetic resonance image (MRI; right) of the temporal bone of two PS patients with EVA are indicated by an arrow in the CT-image, while the MRI shows an enlarged endolymphatic sac. 

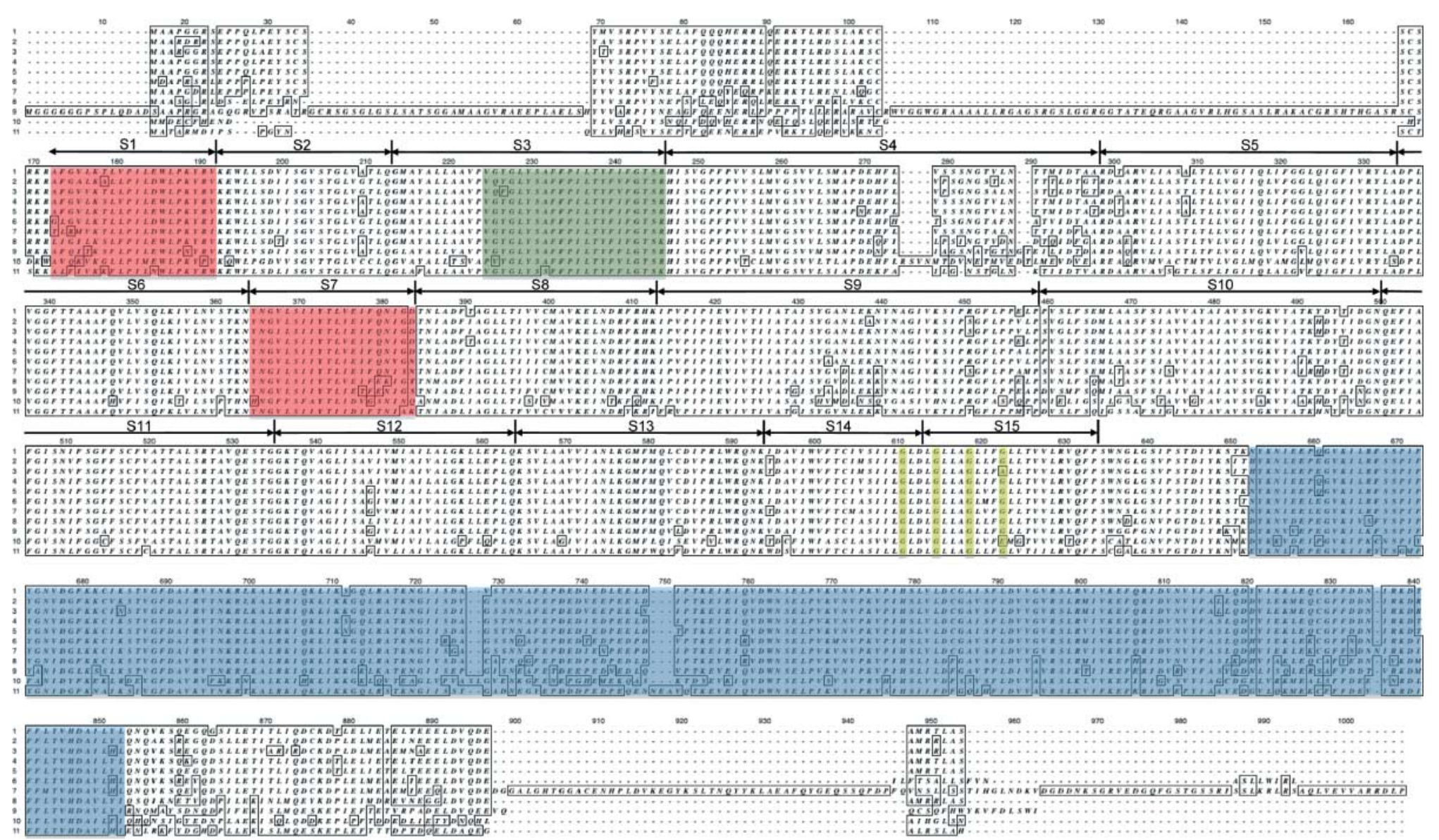

Figure 3 Sequence comparison of SLC26A4 in different species. (1) Homo sapiens (NP_000432), (2) Rattus norvegicus (NP_062087), (3) Mus musculus (NP_035997), (4) Pan troglodytes (XP_519308), (5) Macaca mulatta (XP_001094049), (6) Canis familiaris (XP_540382), (7) Bos taurus (XP_608706), (8) Monodelphis domestica (XP_001363598), (9) Gallus gallus (XP 425419), (10) Danio rerio (XP 692273), and (11) Xenopus laevis (NP 001089008). The 15 putative trans-membrane (TM) helices are indicated with arrows and respective numbering (S1-S15). The two amphipathic helices are boxed in red, and the STAS-domain is boxed in blue. The sulfate-transport-consensus-signature is boxed in green, and the glycine repeat is indicated in yellow. 

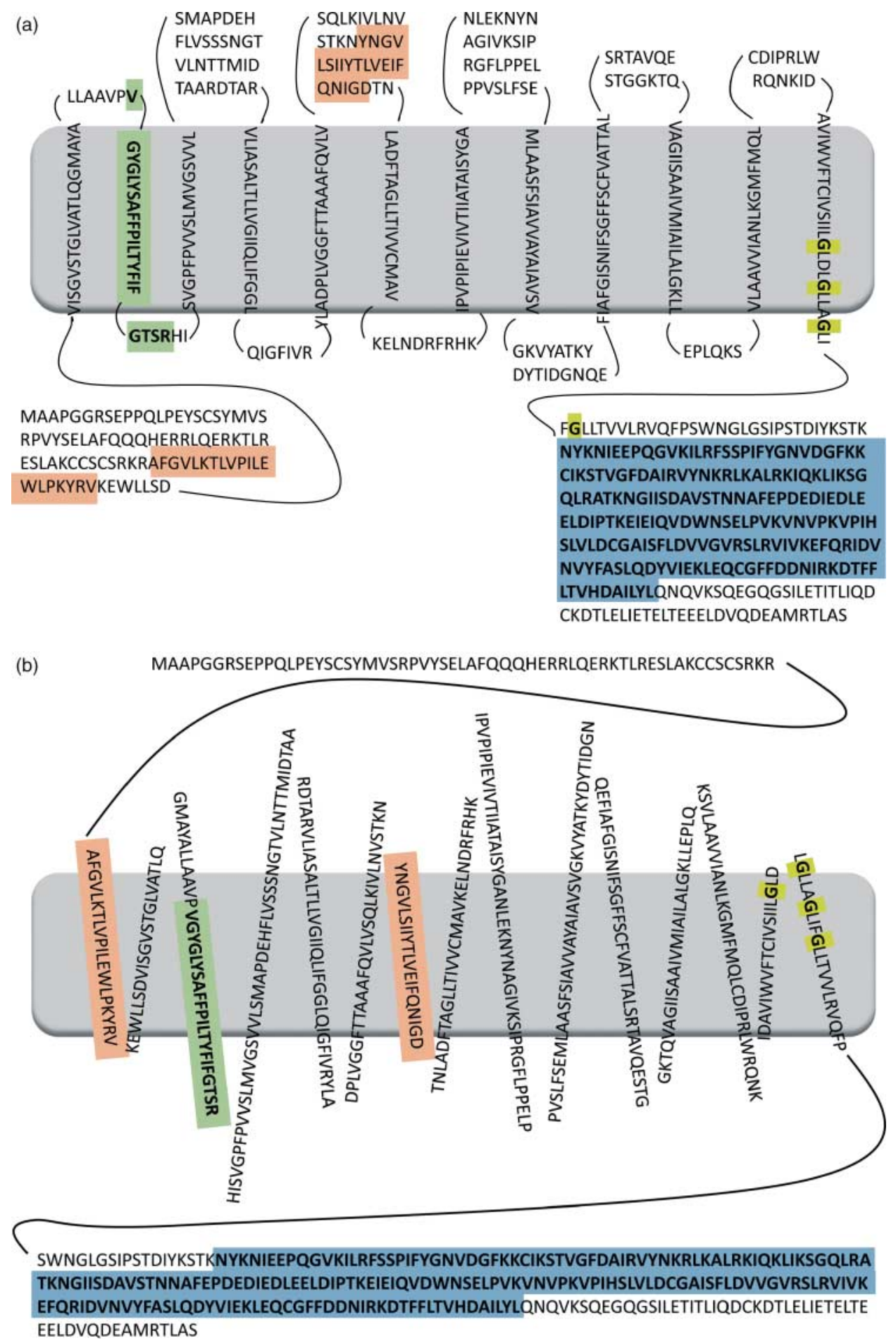

Figure 4 Putative topology of human pendrin. (a) The 12 TM model as described on the Pendred/BOR homepage (http://www.healthcare. uiowa.edu/labs/pendredandbor/domains.htm) using the MEMSAT program. (b) The 15 TM-segment model as proposed in this review. The amino terminus in this model would be located on the extracellular side, and the carboxy terminus would be located at the cytoplasmic side. The 15 trans-membrane (TM) segments are depicted as stretches of amino acids crossing the membrane, which is shown in grey. The position of the TM helices with respect to the membrane (the part of the putative helix that is exposed to the lipid moiety of the membrane) is tentative. The color code of the boxes is equal to that in Fig. 3. It is important to mention that both models are speculative; however, the two models depicted here will help to design experiments, which are needed in order to define the real nature and position of the different TM units. 
Table 1 Sequence of the putative 15 trans-membrane segments, as well as the amino terminal and the carboxy terminal end of human pendrin

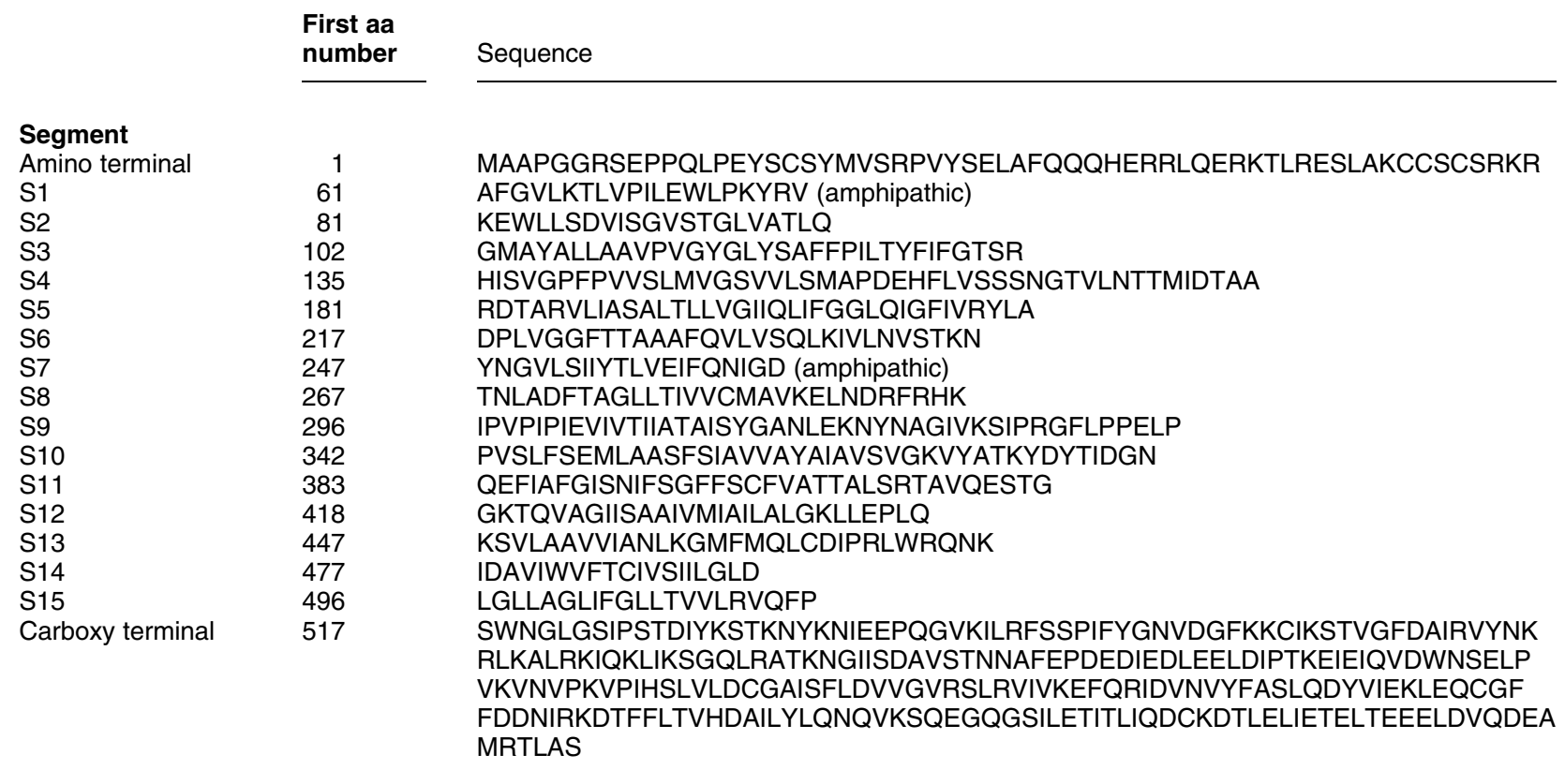

Following treatment with aldosterone analogs, weight gain, and hypertension are observed in SLC26A4 + / + but not in SLC26A4-/ - mice (Wall 2006). Careful studies of renal function after basic and acid loading in PS patients should be performed, and could reveal abnormal handling of anions in the kidney.

No systematic genotype-phenotype correlations have been made so far in PS patients (Lopez-Bigas et al. 1999, Masmoudi et al. 2000, Fugazzola et al. 2007). This review is an attempt to summarize the functional data available as of now for pendrin and its mutants, and to correlate these data to the genotype identified, with the hope that this information will help clinicians to better treat PS patients.

\section{The molecular entity responsible for Pendred syndrome: structural aspects}

The clinical patterns described at the level of the thyroid gland and the inner ear are the result of decreases in pendrin function (Everett et al. 1997), a protein encoded by the SLC26A4 gene (NM_000441). There is a high degree of similarity between pendrin in different species. Figure 3 shows the amino acid sequences of pendrin from Homo sapiens, Rattus norvegicus, Mus musculus, Pan troglodytes, Macaca mulatta, Canis familiaris, Bos taurus, Monodelphis domestica, Gallus gallus, Danio rerio, and Xenopus laevis. The respective similarities if compared with the human sequence are $72.5 \%$, with $P$. troglodytes and M. mulatta being $98.8 \%$ similar, and $R$. norvegicus, M. musculus, C. familiaris, and M. domestica being $\geq 90 \%$ similar (the similarity plot was done by ClustalW; MacVector). Structural information regarding membrane topology of pendrin is limited and controversial. Whereas Everett et al. (1997) suggest a 11 TM-segment model with the carboxy (C)-terminus at the extracellular site using the PHDhtm program, Royaux et al. (2000) suggest a 12 TM model, with the C-terminus at the cytoplasmatic site. A similar 12 TM model is suggested on the Pendred/BOR homepage (http://www.healthcare.uiowa.edu/labs/ pendredandbor/domains.htm) using the MEMSAT program (Zhai \& Saier 2001; Fig. 4a). This program, however, predicts an additional 13th TM segment located in the sulfate-transporters-antisigma-factorantagonist (STAS)-domain of SLC26A4 (Aravind \& Koonin 2000), a sequence highly similar to the antisigma-factor-antagonist in bacteria. This sequence is believed to be involved in NTP binding and/or hydrolysis. Aravind \& Koonin (2000) postulate that the STAS domain in SLC26-family members could possibly regulate anion-transport by sensing intracellular concentrations of GTP and/or ATP. Furthermore, it was hypothesized that the STAS domain is involved in the interaction of SLC26 members with the cystic-fibrosis-transmembrane-regulator (Ko et al. 2002, 2004); however, the exact function of this domain is still unclear. The 13th TM would bring the C-terminus toward the extracellular site and would therefore be in contrast to the experimental data provided by Gillam 
Table 2 Summary of all functionally characterized allelic variants of SLC26A4

Pathology

Localization

S28R

E29Q

V88I

$\mathrm{FS} 93>96 \mathrm{X}^{\mathrm{f}}+$

C416-1G_A ${ }^{9}$

G102R

L117F

V138F

$\mathrm{P} 140 \mathrm{H}$

P142R

M147V

$\mathrm{S} 166 \mathrm{~N}$

G209V

L236P

$\begin{array}{ll} & \text { PS } \\ & \\ \text { FS297 }>302 X & \text { PS, EVA } \\ \text { F335L } & \text { EVA } \\ \text { FS306 }>309 X & \text { PS } \\ \text { E384G } & \text { PS }\end{array}$

$\begin{array}{ll} & \text { EVA } \\ \mathrm{R} 409 \mathrm{H} & \mathrm{PS}\end{array}$

$\begin{array}{ll}\text { V88I/R409H } & \text { m } \\ \text { T410M } & \text { EVA } \\ \text { Q413P } & \text { EV } \\ \text { T416P } & \text { PS }\end{array}$

$\begin{array}{lll} & \text { EVA } & \text { Intracellular }^{\text {d }} \\ \text { G424D } & \text { PS } & \\ \text { Q446R } & \text { EVA } & \text { ER }^{\mathrm{j}} \\ \text { V480D } & \text { EVA } & \\ \text { T485R } & \text { PS } & \\ \text { I490L } & \text { EVA } & \\ \text { G497S } & \text { EVA } & \text { Intracellular }\end{array}$

$\begin{array}{lll} & & \\ & & \\ \text { 1490L+G497S } & \text { EVA } & \\ \text { Q514K } & \text { EVA, PS } & \\ \text { FS523>548X } & \text { PS } & \\ \text { Y556C } & \text { PS } & \text { Partially PM }^{j} \\ \text { C565Y } & \text { EVA } & \text { PM }^{j} \\ \text { L597S } & \text { Controls only } & \text { PM }^{j} \\ & \text { EVA } & \\ & \text { EVA } & \\ \text { E625X } & \text { EVA } & \\ \text { V653A } & & \end{array}$

$E R^{j}$

Intracellular $^{\mathrm{d}}$

$P M^{\mathrm{j}}$

Intracellular ${ }^{\mathrm{j}}$

$E R^{j}$

Intracellular ${ }^{\text {d }}$

Partially $\mathrm{PM}^{\mathrm{a}}$

$E R^{j}$

EVA

PS

$E^{\mathrm{j}}$
Function

Loss of chloride uptake ${ }^{\mathrm{b}}$

Loss of chloride and iodide transport ${ }^{\mathrm{C}}$

Loss of $\mathrm{Cl}^{-} / \mathrm{HCO}_{3}^{-}$exchange activity ${ }^{\mathrm{e}}$

Reduction of the chloride and iodide transport ${ }^{c}$

Chloride and iodide transport not reduced ${ }^{\mathrm{C}}$

Intracellular iodine retention (primary

thyrocytes culture $)^{\mathrm{i}}$

Loss of lodide efflux ${ }^{k}$

lodide efflux equal to $w t^{k}$

Loss of iodide efflux ${ }^{k}$

Loss of chloride and iodide transport ${ }^{\mathrm{c}}$

Loss of $\mathrm{Cl}^{-} / \mathrm{HCO}_{3}^{-}$exchange activity ${ }^{\mathrm{e}}$

Loss of $\mathrm{Cl}^{-} / \mathrm{HCO}_{3}^{-}$exchange activity

$\mathrm{Cl}^{-} / \mathrm{HCO}_{3}^{-}$exchange activity not different

from wt ${ }^{\mathrm{e}}$

Reduction of iodide efflux ${ }^{k}$

Loss of iodide efflux ${ }^{k}$

Loss of chloride and iodide uptake $\mathrm{e}^{\mathrm{b}, \mathrm{i}}$

Loss of $\mathrm{Cl}^{-} / \mathrm{HCO}_{3}^{-}$exchange activity

Loss of $\mathrm{Cl}^{-} / \mathrm{I}^{-}$exchange activity

Loss of iodide efflux ${ }^{k}$

Reduction of $\mathrm{Cl}^{-} / \mathrm{I}^{-}$and $\mathrm{Cl}^{-} / \mathrm{HCO}_{3}^{-}$

exchange activity'

Loss of iodide efflux ${ }^{k}$

Loss of chloride and iodide uptake $e^{\text {b, }}$

Loss of $\mathrm{Cl}^{-} / \mathrm{HCO}_{3}^{-}$exchange activity

Loss of $\mathrm{Cl}^{-} / \mathrm{I}^{-}$exchange activity

Loss of iodide efflux ${ }^{k}$

Reduction of iodide and chloride transport ${ }^{\mathrm{C}}$

Reduction of the chloride and iodide transport ${ }^{\mathrm{C}}$

Loss of iodide efflux ${ }^{k}$

Loss of chloride and iodide transport ${ }^{\mathrm{c}}$

Loss of chloride and iodide uptake ${ }^{\mathrm{b}, \mathrm{i}}$

Loss of $\mathrm{Cl}^{-} / \mathrm{HCO}_{3}^{-}$exchange activity ${ }^{\mathrm{e}}$

Loss of $\mathrm{Cl}^{-} / \mathrm{I}^{-}$exchange activity

Reduction of the chloride and iodide transport ${ }^{\mathrm{C}}$

Loss of iodide efflux ${ }^{k}$

Reduction of chloride and iodide uptake $e^{b, i}$

Reduction of the chloride and iodide transport $^{\mathrm{C}}$

Mild reduction of chloride and iodide uptake ${ }^{b, i}$

Strong reduction of chloride and iodide uptake ${ }^{\mathrm{b}, \mathrm{i}}$

Loss of $\mathrm{Cl}^{-} / \mathrm{HCO}_{3}^{-}$

exchange activity

Strong reduction of chloride and iodide uptake

Loss of chloride and iodide transport ${ }^{\mathrm{c}}$

Loss of chloride and iodide transport ${ }^{\mathrm{C}}$

Loss of iodide efflux ${ }^{k}$

Reduction of $\mathrm{Cl}^{-} / \mathrm{I}^{-}$and $\mathrm{Cl}^{-} / \mathrm{HCO}_{3}^{-}$

exchange activity'

Chloride and iodide transport not

different from $w^{c}{ }^{c}$

Reduction of $\mathrm{Cl}^{-} / \mathrm{I}^{-}$and $\mathrm{Cl}^{-} / \mathrm{HCO}_{3}^{-}$

exchange activity'

Loss of $\mathrm{Cl}^{-} / \mathrm{HCO}_{3}^{-}$exchange activity ${ }^{\mathrm{e}}$

Reduction of chloride and iodide uptake $\mathrm{b}^{\mathrm{b}, \mathrm{i}}$
References

Dossena et al. (2006a,b)

and Yoon et al. (2008)

Pera et al. (2008)

Pera et al. (2008)

Palos et al. (2008)

Taylor et al. (2002)

Taylor et al. (2002)

Taylor et al. (2002)

Pera et al. (2008)

Yoon et al. (2008)

Yoon et al. (2008)

Yoon et al. (2008)

Taylor et al. (2002)

Scott et al. (2000)

Taylor et al. (2002)

Rotman-Pikielny et al. (2002)

Choi et al. (2008) and

Yoon et al. (2008)

Gillam et al. (2005)

Choi et al. (2008)

Gillam et al. (2004)

Scott et al. (2000)

Rotman-Pikielny et al. (2002)

Choi et al. (2008) and

Yoon et al. (2008)

Gillam et al. (2005) and

Dossena S \& Paulmichl M

(personal communication)

Pera et al. (2008)

Taylor et al. (2002)

Pera et al. (2008)

Scott et al. (2000),

Rotman-Pikielny et al. (2002)

Choi et al. (2008) and

Yoon et al. (2008)

Pera et al. (2008)

Taylor et al. (2002)

Scott et al. (2000)

Pera et al. (2008)

Scott et al. (2000)

Scott et al. (2000) and

Yoon et al. (2008)

Scott et al. (2000)

Pera et al. (2008)

Fugazzola et al. (2007)

Taylor et al. (2002)

Choi et al. (2008)

Choi et al. (2008) and

Pera et al. (2008)

Yoon et al. (2008)

Scott et al. (2000) 


\begin{tabular}{|c|c|c|c|c|}
\hline & Pathology & Localization & Function & References \\
\hline \multicolumn{5}{|l|}{ Mutation } \\
\hline L676Q & PS & Intracellular & Loss of iodide efflux ${ }^{k}$ & Gillam et al. (2004) and \\
\hline & PS? & Intracellular ${ }^{\mathrm{d}}$ & Loss of $\mathrm{Cl}^{-} / \mathrm{HCO}_{3}^{-}$exchange activity & Yoon et al. (2008) \\
\hline $\mathrm{H} 723 \mathrm{R}$ & PS & Intracellular ${ }^{d}$ & Loss of $\mathrm{Cl}^{-} / \mathrm{HCO}_{3}^{-}$exchange activity & Yoon et al. (2008) \\
\hline D724G & EVA & & Loss of chloride and iodide transport ${ }^{\mathrm{C}}$ & Pera et al. (2008) \\
\hline $\mathrm{R} 776 \mathrm{C}$ & TPO mut. EVA & $P M^{j}$ & $\begin{array}{l}\text { lodide efflux equal to } \mathrm{wt}^{\mathrm{k}} \\
\text { Reduction of } \mathrm{Cl}^{-} / \mathrm{I}^{-} \text {and } \mathrm{Cl}^{-} / \mathrm{HCO}_{3}^{-} \\
\text {exchange activity }\end{array}$ & $\begin{array}{l}\text { Pfarr et al. (2006) and } \\
\text { Choi et al. (2008) }\end{array}$ \\
\hline
\end{tabular}

\author{
aWestern blot. \\ ${ }^{\text {b36 }} \mathrm{Cl}^{-}$uptake. \\ cFluorometric method. \\ ${ }^{\mathrm{d}} \mathrm{N}$-glycosylation. \\ e Measure of the $\mathrm{pH}_{\mathrm{i}}$ (BCECF). \\ ${ }^{f}$ Originally reported as: c.279delT. \\ ${ }^{9}$ Acceptor splice site mutation. \\ ${ }^{\mathrm{h}}$ Confocal microscopy. \\ ${ }^{i 125} \mathrm{I}^{-}$uptake. \\ jGFP-fusion protein. \\ k125 $\mathrm{I}^{-}$efflux. \\ ${ }^{136} \mathrm{Cl}^{-}$efflux (rate constant evaluation). \\ ${ }^{m}$ Both mutations are present on the same molecule. \\ ${ }^{\mathrm{n}}$ Mutations are present on different alleles.
}

et al. (2004), and therefore it was probably ignored in the 12 TM model using the MEMSAT program. Here, we show another putative model of SLC26A4, using the MEMSAT prediction as a starting point and after refining the model according Sweet \& Eisenberg (1983), and Shafrir \& Guy (2004). In this model, SLC26A4 would be formed by up to $15 \mathrm{TM}$ helical segments (Table 1 and Fig. 4b). The TM segments marked amphipathic are the most ambiguous in terms of their localization, which could be transmembrane, cytosolic, or extracellular. However, since the sequence homology of these segments between the different species is very high (Fig. 3), it could be assumed that these segments could indeed form TM helices as opposed to helices located on either surface of the membrane. However, more rigorous experiments are needed to distinguish between the different possibilities. By assuming that the C-terminus is located within the cytosol, the amino terminus would have to be located on the extracellular side in both the $15 \mathrm{TM}$ and 13 TM (minus the two amphipathic helices) models. This is in direct contrast to the model suggested by Gillam, in which the amino terminus is located within the cytosol (Gillam et al. 2004). Again, all the SLC26A4 models proposed so far, including our model proposed here, are speculative and lack experimental evidence; therefore, more rigorous experiments are necessary to unambiguously determine the secondary and tertiary structure of SLC26A4. The third TM segment in Fig. 4b harbors the sulfate-transport-consensus-signature (Mount
\& Romero 2004), a stretch of amino acids involved in the transport of sulfate in SLC26A1, A2, A3, A6-9, and A11 (Mount \& Romero 2004). This sequence is, however, modified in SLC26A4, which is consistent with the data showing that pendrin does not transport sulfate (Scott et al. 1999, Bogazzi et al. 2000, Scott \& Karniski 2000). An additional structural aspect of pendrin, as shown in Figs 3 and $4 \mathrm{~b}$, is the presence of glycines at every fourth position in the putative TM segment 15 (boxed in yellow in Figs 3 and 4b). It is possible that the arrangement of these amino acids may play a role in the homodimerization of the protein. The product of a wild-type allele could be functionally hampered if dimerized with the product of a mutated allele. This is of particular significance when considering the discussion by Scott $e t$ al. (2000), which describes that the combination of certain SLC26A4 mutations could be dominant negative.

\section{Genetics of Pendred syndrome}

Presently, more than 140 mutations in the SLC26A4 gene have been described (www.healthcare.uiowa.edu/ labs/pendredandbor) in PS and EVA, which have been detected within the coding sequence, splice sites, non-coding exon 1, and within the FOXI1 binding transcriptional regulatory elements (Yang et al. 2007). Approximately $62 \%$ of all mutations are missense changes, most of which have been described in single families. 

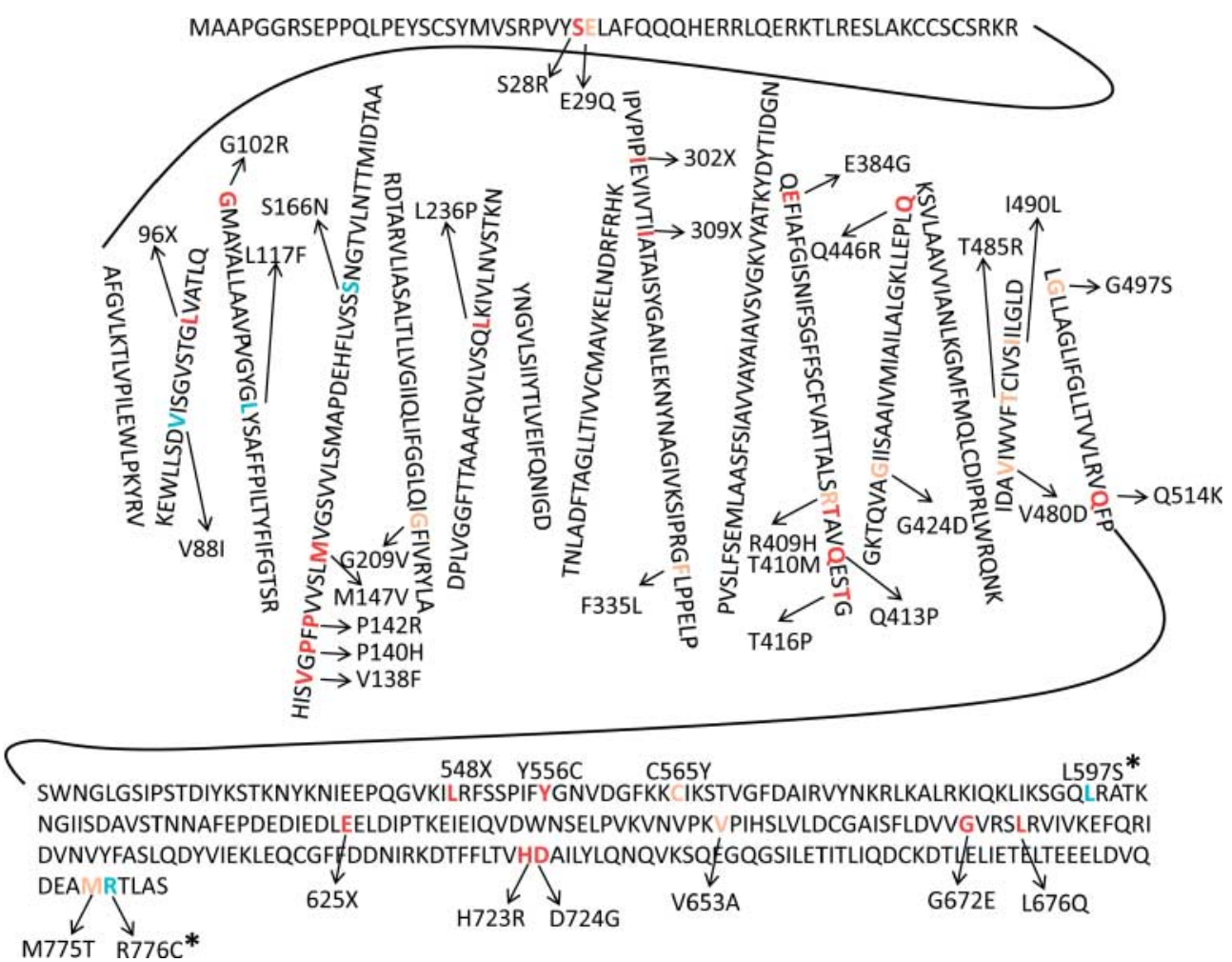

Figure 5 Topology of the functionally characterized SLC26A4 mutations. The putative model is taken from Fig. 4 and the respective mutations are indicated. Light blue indicates the mutations with no functional impact, i.e. those mutations indistinguishable from wild-type. In orange are those mutations with a reduced function and in red are those mutations leading pendrin un-functional. The extension ' $X$ ' indicates the mutations that lead to a truncation in the SLC26A4 sequence. *Allelic variants described as polymorphisms but whose functionality is not unambiguous (Choi et al. 2008).

\section{Functional characterization of pendrin}

As described earlier, pendrin is involved in anion transport within the ear, thyroid, and kidney. It was shown that human pendrin expressed in monkey cells leads to chloride currents (Yoshida et al. 2002). However, we showed that human pendrin expressed in human cells does not lead to the activation of chloride currents, but by contrast leads to an increase in cationic currents. The latter experiments suggest that SLC26A4 induced chloride transport is per se electroneutral when expressed in human cellular systems (for more details, see Dossena et al. (2005)). Since the exact coupling ratio and hence rheogeneity of pendrin is still in debate, it would be desirable to investigate the electrical behavior of SLC26A4 expressed in a polarized epithelium, since the electrophysiological studies performed so far in non-polarized cells might not reflect the physiological 'context' of SLC26A4 function. The only study in which Pendrin function was investigated in a polarized epithelium was published by Gillam et al. (2004), in which they assessed the basolateral to apical flux of radioactive iodide.
The authors hypothesized in their study that the SLC26A4-mediated transport could be electroneutral or mediated via channels, which would imply rheogenic transport. We also used a radioactive-flux technique to characterize wild-type and mutant SLC26A4 functions (Dossena et al. 2006b) and from these and the results mentioned above, we can conclude that the SLC26A4mediated transport is electroneutral.

\section{Can pendrin function be predicted by genotype?}

The two criteria used so far for assuming pathogenicity of SLC26A4 gene mutations are i) low incidence of the mutation in the control population and ii) substitution of evolutionary conserved amino acids. However, we recently showed that these criteria are not reliable parameters for predicting SLC26A4 function (Pera et al. 2008). In Table 2, we have summarized all the SLC26A4 mutations for which functional data are available at the moment. The tests used for determining SLC26A4 transporter functionality range from 
radioactive flux studies and localization in cells to assays utilizing intracellular fluorescent indicators to sense changes in halide and/or proton amounts (Table 2; it is important to note that the concentration of iodide in the different tests changes from very low (radioactive flux studies) to very high (fluorometric method)). The different techniques are consistent with each other and showed that entire proteins, not just the presumed transmembrane elements, are crucial for proper function. As shown in Fig. 5, deleterious mutations have been detected from amino acid 28 through amino acid 724 out of the 780 residue-long pendrin transporter. The hypothesis that the entire protein seems to be important is further substantiated in that all mutations leading to truncations are functionally inactive (Fig. 5). It is difficult at the moment to unambiguously link the severity of hearing loss (moderate, severe, and profound) to individual SLC26A4 mutations. Mutations with no transport activity (P140H, Q413P, Q514K, and D724G) and with reduced activity (E29Q, V88I/R409H, G424D, and T485R) are equally identified in patients with PS and ns-EVA suffering from moderate to profound hearing loss (Taylor et al. 2002, Pera et al. 2008a). The simplest explanation for the difficulty in correlating a specific SLC26A4 mutation to clinical symptoms is that additional genetic-, epigenetic-, and/or environmental factors could substantially modify the observed disease phenotype (Pera et al. 2008a). This is further corroborated in that SLC26A4 zero mutants can show EVA and severe hearing loss, and patients with mono-allelic SLC26A4 mutations can show severe to profound hearing loss without EVA (Pera et al. 2008a). Accordingly, Pryor et al. (2005) found that at least some cases of non-syndromic EVA are associated with a single SLC26A4 mutation, whereas PS is a genetically homogeneous disorder caused by biallelic SLC26A4 mutations. It should be noted that patients thought to have a monoallelic mutation may have an undetected mutation in a regulatory or intronic region (Gillam et al. 2005, Pryor et al. 2005). Despite the fact that it is difficult at the moment to correlate genotype (SLC26A4) and phenotype (moderate to profound hearing loss), it is noteworthy to mention that a patient homozygous for the Q514K mutation (loss-of-function) showed bilateral, sensorineural, and profound deafness at the age of 2, whereas a separate patient, we described, carrying two mutations with only reduced transport activity (E29Q and V88I/R409H), had sensorineuronal, moderate/ mild hearing loss at the age of 44 (Pera et al. 2008a). These data indicate that the functional tests could indeed help explain the severity of particular pendrin mutations.

Our former work (Pera et al. 2008a) suggested that certain biochemical parameters could explain some functional impairments. For example, in all mutations depicted in Fig. 5, an impairment in transport function was found if an amino acid bearing a fixed charge (aspartic acid $\left(\mathrm{D}^{-}\right)$or glutamic acid $\left(\mathrm{E}^{-}\right)$, lysine $\left(\mathrm{K}^{+}\right)$ or arginine $\left(\mathrm{R}^{+}\right)$, and histidine $\left(\mathrm{H}^{+}\right)$single letter code, and the sign indicates the fixed charge; the positive charge of histidine depends on the $\mathrm{pH}$ ) was missing or introduced. Furthermore, the loss or inclusion of a proline ( $\mathrm{P}$; proline acts as a structural disruptor of regular secondary structures such as $\alpha$-helices or $\beta$-sheets) in the SLC26A4 sequence is detrimental for transport function. However, Pfarr et al. (2006) described one exception, in which an allelic variant (R776C; Fig. 5) functioned like the controls. Interestingly, this particular arginine is located on the extreme C-terminus of SLC26A4 (a 780 amino acid protein). The N- and C-termini of a protein are usually not structurally defined; therefore, it is plausible to assume that mutations occurring in these areas probably have little or no functional impact.

It is important to note that mutations which do not enter into this 'proline/fixed charge' role can be functionally detrimental or without functional implication (Scott et al. 2000, Taylor et al. 2002, Gillam et al. 2004, Pfarr et al. 2006, Fugazzola et al. 2007). In Fig. 5, this applies for 12 out of the 36 mutations for which a functional reduction was described. In these roughly $33 \%$ of the cases, only functional tests can unambiguously distinguish between SLC26A4 singlenucleotide-polymorphisms and those mutations that actually cause a reduced function and ultimately signs of disease.

In conclusion, it has become apparent that the two parameters used so far, i.e. i) low incidence of the mutation in the control population and ii) substitution of evolutionary conserved amino acids by the mutation, are not reliable for predicting SLC26A4 transport function. The findings summarized here reveal that the 'proline/fixed charge' role, i.e. the addition or omission of proline, or the addition or omission of charged amino acids in the sequence of SLC26A4, might be a better option for predicting SLC26A4 function in the cases where direct functional tests cannot be performed.

\section{Declaration of interest}

The authors declare that there is no conflict of interest that could be perceived as prejudicing the impartiality of the research reported.

\section{Funding}

This work was supported by the Italian Ministry of Instruction, University and Research (MIUR, prot 2003060317), the Austrian Science Fund (FWF: P18608-B05), and the PMU research fund. 


\section{Acknowledgements}

We would like to thank Seth Alper (Harvard) and Andy Griffith (NIH) for sharing their manuscripts prior to publication. We thank H Robert Guy for assistance in analyzing the sequence and for comment about the manuscript. Charity Nofziger is supported be the Lise Meitner stipend of the FWF (M1108-B11).

This work is dedicated to Helga and Erich Kellerhals.

\section{References}

Aravind L \& Koonin EV 2000 The STAS domain - a link between anion transporters and antisigma-factor antagonists. Current Biology 10 R53-R55.

Batsakis JG \& Nishiyama RH 1962 Deafness with sporadic goiter. Pendred's syndrome. Archives of Otolaryngology 76 401-406.

Blons H, Feldmann D, Duval V, Messaz O, Denoyelle F, Loundon N, Sergout-Allaoui A, Houang M, Duriez F, Lacombe D et al. 2004 Screening of SLC26A4 (PDS) gene in Pendred's syndrome: a large spectrum of mutations in France and phenotypic heterogeneity. Clinical Genetics 66 333-340.

Bogazzi F, Bartalena L, Raggi F, Ultimieri F \& Martino E 2000 Pendrin does not increase sulfate uptake in mammalian COS-7 cells. Journal of Endocrinological Investigation 23 170-172.

Campbell C, Cucci RA, Prasad S, Green GE, Edeal JB, Galer CE, Karniski LP, Sheffield VC \& Smith RJ 2001 Pendred syndrome, DFNB4, and PDS/SLC26A4 identification of eight novel mutations and possible genotype-phenotype correlations. Human Mutation 17 403-411.

Cantone A, Wang T, Pica A, Simeoni M \& Capasso G 2006 Use of transgenic mice in acid-base balance studies. Journal of Nephrology 19 S121-S127.

Choi B, Stewart A, Madeo A, Yang Y, Pryor S, Lenhard S, Kittles R, Eisenman D, Kim H, Niparko J et al. 2008 SLC26A4 variants associated with nonsyndromic hearing loss and enlargement of the vestibular aqueduct: genotype-phenotype correlation or coincidental polymorphisms? Human Mutation 30 599-608.

Dossena S, Maccagni A, Vezzoli V, Bazzini C, Garavaglia ML, Meyer G, Furst J, Ritter M, Fugazzola L, Persani L et al. 2005 The expression of wild-type pendrin (SLC26A4) in human embryonic kidney (HEK 293 Phoenix) cells leads to the activation of cationic currents. European Journal of Endocrinology 153 693-699.

Dossena S, Rodighiero S, Vezzoli V, Bazzini C, Sironi C, Meyer G, Furst J, Ritter M, Garavaglia ML, Fugazzola L et al. 2006 $a$ Fast fluorometric method for measuring pendrin (SLC26A4) $\mathrm{Cl}^{-} / \mathrm{I}^{-}$ transport activity. Cellular Physiology and Biochemistry 18 67-74.

Dossena S, Vezzoli V, Cerutti N, Bazzini C, Tosco M, Sironi C, Rodighiero S, Meyer G, Fascio U, Fürst J et al. 2006b Functional characterization of wild-type and a mutated form of SLC26A4 identified in a patient with Pendred syndrome. Cellular Physiology and Biochemistry 17 245-256.

Everett LA, Glaser B, Beck JC, Idol JR, Buchs A, Heyman M, Adawi F, Hazani E, Nassir E, Baxevanis AD et al. 1997 Pendred syndrome is caused by mutations in a putative sulphate transporter gene (PDS). Nature Genetics 17 411-422.

Everett LA, Morsli H, Wu DK \& Green ED 1999 Expression pattern of the mouse ortholog of the Pendred's syndrome gene (Pds) suggests a key role for pendrin in the inner ear. PNAS 96 9727-9732.

Everett LA, Belyantseva IA, Noben-Trauth K, Cantos R, Chen A, Thakkar SI, Hoogstraten-Miller SL, Kachar B, Wu DK \& Green ED 2001 Targeted disruption of mouse Pds provides insight about the inner-ear defects encountered in Pendred syndrome. Human Molecular Genetics 10 153-161.

Fraser GR 1965 Association of congenital deafness with goitre (Pendred's syndrome) a study of 207 families. Annals of Human Genetics 28 201-249.
Fugazzola L, Mannavola D, Cerutti N, Maghnie M, Pagella F, Bianchi P, Weber G, Persani L \& Beck-Peccoz P 2000 Molecular analysis of the Pendred's syndrome gene and magnetic resonance imaging studies of the inner ear are essential for the diagnosis of true Pendred's syndrome. Journal of Clinical Endocrinology and Metabolism $\mathbf{8 5}$ 2469-2475.

Fugazzola L, Cerutti N, Mannavola D, Vannucchi G \& Beck-Peccoz P 2001 The role of pendrin in iodide regulation. Experimental and Clinical Endocrinology and Diabetes 109 18-22.

Fugazzola L, Cirello V, Dossena S, Rodighiero S, Muzza M, Castorina P, Lalatta F, Ambrosetti U, Beck-Peccoz P, Botta G et al. 2007 High phenotypic intrafamilial variability in patients with Pendred syndrome and a novel duplication in the SLC26A4 gene: clinical characterization and functional studies of the mutated SLC26A4 protein. European Journal of Endocrinology 157 331-338.

Gillam MP, Sidhaye AR, Lee EJ, Rutishauser J, Stephan CW \& Kopp P 2004 Functional characterization of pendrin in a polarized cell system. Evidence for pendrin-mediated apical iodide efflux. Journal of Biological Chemistry 279 13004-13010.

Gillam MP, Bartolone L, Kopp P \& Bevenga S 2005 Molecular analysis of the PDS gene in a nonconsanguineous Sicilian family with Pendred's syndrome. Thyroid 15 734-741.

Golstein P, Abramow M, Dumont JE \& Beauwens R 1992 The iodide channel of the thyroid: a plasma membrane vesicle study. American Journal of Physiology 263 C590-C597.

Grimaldi R, Capuano P, Miranda N, Wagner C \& Capasso G 2007 Pendrin: physiology, molecular biology and clinical importance. Giornale Italiano di Nefrologia 24 288-294.

Hughey RP \& Kleyman TR 2007 Functional cross talk between ENaC and pendrin. American Journal of Physiology. Renal Physiology 293 F1439-F1440.

Illum P, Kiaer HW, Hvidberg-Hansen J \& Sondergaard G 1972 Fifteen cases of Pendred's syndrome. Congenital deafness and sporadic goiter. Archives of Otolaryngology 96 297-304.

Kim YH, Kwon TH, Frische S, Kim J, Tisher CC, Madsen KM \& Nielsen S 2002 Immunocytochemical localization of pendrin in intercalated cell subtypes in rat and mouse kidney. American Journal of Physiology. Renal Physiology 283 F744-F754.

Kim YH, Verlander JW, Matthews SW, Kurtz I, Shin W, Weiner ID, Everett LA, Green ED, Nielsen S \& Wall SM 2005 Intercalated cell $\mathrm{H}+/ \mathrm{OH}-$ transporter expression is reduced in Slc26a4 null mice. American Journal of Physiology. Renal Physiology $\mathbf{2 8 9}$ F1262-F1272.

Ko SB, Shcheynikov N, Choi JY, Luo X, Ishibashi K, Thomas PJ, Kim JY, Kim KH, Lee MG, Naruse $S$ et al. 2002 A molecular mechanism for aberrant CFTR-dependent $\mathrm{HCO}(3)(-)$ transport in cystic fibrosis. EMBO Journal 21 5662-5672.

Ko SB, Zeng W, Dorwart MR, Luo X, Kim KH, Millen L, Goto H, Naruse S, Soyombo A, Thomas PJ et al. 2004 Gating of CFTR by the STAS domain of SLC26 transporters. Nature Cell Biology 6 343-350.

Kopp P, Pesce L \& Solis SJ 2008 Pendred syndrome and iodide transport in the thyroid. Trends in Endocrinology and Metabolism 19 260-268.

Lopez-Bigas N, Rabionet R, de Cid R, Govea N, Gasparini P, Zelante L, Arbones ML \& Estivill X 1999 Splice-site mutation in the PDS gene may result in intrafamilial variability for deafness in Pendred syndrome. Human Mutation 14 520-526.

Masmoudi S, Charfedine I, Hmani M, Grati M, Ghorbel AM, ElgaiedBoulila A, Drira M, Hardelin JP \& Ayadi H 2000 Pendred syndrome: phenotypic variability in two families carrying the same PDS missense mutation. American Journal of Medical Genetics 90 $38-44$.

Mount DB \& Romero MF 2004 The SLC26 gene family of multifunctional anion exchangers. Pflügers Archiv 447 710-721.

Napiontek U, Borck G, Muller-Forell W, Pfarr N, Bohnert A, Keilmann A \& Pohlenz J 2004 Intrafamilial variability of the deafness and 
goiter phenotype in Pendred syndrome caused by a T416P mutation in the SLC26A4 gene. Journal of Clinical Endocrinology and Metabolism 89 5347-5351.

Palos F, Garcia-Rendueles ME, Araujo-Vilar D, Obregon MJ, Calvo RM, Cameselle-Teijeiro J, Bravo SB, Perez-Guerra O, Loidi L, Czarnocka B et al. 2008 Pendred syndrome in two Galician families: insights into clinical phenotypes through cellular, genetic, and molecular studies. Journal of Clinical Endocrinology and Metabolism 93 267-277.

Pendred V 1896 Deaf-mutism and goiter. Lancet 148532.

Pera A, Dossena S, Rodighiero S, Gandia M, Botta G, Meyer G, Moreno F, Nofziger C, Hernandez-Chico C \& Paulmichl M 2008 Functional assessment of allelic variants in the SLC26A4 gene involved in Pendred syndrome and nonsyndromic EVA. PNAS 105 18608-18613.

Pfarr N, Borck G, Turk A, Napiontek U, Keilmann A, Muller-Forell W, Kopp P \& Pohlenz J 2006 Goitrous congenital hypothyroidism and hearing impairment associated with mutations in the TPO and SLC26A4/PDS genes. Journal of Clinical Endocrinology and Metabolism 91 2678-2681

Phelps PD, Coffey RA, Trembath RC, Luxon LM, Grossman AB, Britton KE, Kendall-Taylor P, Graham JM, Cadge BC, Stephens SG et al. 1998 Radiological malformations of the ear in Pendred syndrome. Clinical Radiology 53 268-273.

Pryor SP, Madeo AC, Reynolds JC, Sarlis NJ, Arnos KS, Nance WE, Yang Y, Zalewski CK, Brewer CC, Butman JA et al. 2005 SLC26A4/PDS genotype-phenotype correlation in hearing loss with enlargement of the vestibular aqueduct (EVA): evidence that Pendred syndrome and non-syndromic EVA are distinct clinical and genetic entities. Journal of Medical Genetics 42 159-165.

Reardon W, Coffey R, Phelps PD, Luxon LM, Stephens D, KendallTaylor P, Britton KE, Grossman A \& Trembath R 1997 Pendred syndrome - 100 years of underascertainment? Quarterly Journal of Medicine 90 443-447.

Rotman-Pikielny P, Hirschberg K, Maruvada P, Suzuki K, Royaux IE, Green ED, Kohn LD, Lippincott-Schwartz J \& Yen PM 2002 Retention of pendrin in the endoplasmic reticulum is a major mechanism for Pendred syndrome. Human Molecular Genetics 11 2625-2633.

Royaux IE, Suzuki K, Mori A, Katoh R, Everett LA, Kohn LD \& Green ED 2000 Pendrin, the protein encoded by the Pendred syndrome gene (PDS), is an apical porter of iodide in the thyroid and is regulated by thyroglobulin in FRTL-5 cells. Endocrinology 141 839-845.

Royaux IE, Wall SM, Karniski LP, Everett LA, Suzuki K, Knepper MA \& Green ED 2001 Pendrin, encoded by the Pendred syndrome gene, resides in the apical region of renal intercalated cells and mediates bicarbonate secretion. PNAS 98 4221-4226.

Scott DA \& Karniski LP 2000 Human pendrin expressed in Xenopus laevis oocytes mediates chloride/formate exchange. American Journal of Physiology. Cell Physiology 278 C207-C211.

Scott DA, Wang R, Kreman TM, Sheffield VC \& Karniski LP 1999 The Pendred syndrome gene encodes a chloride-iodide transport protein. Nature Genetics 21 440-443.

Scott DA, Wang R, Kreman TM, Andrews M, McDonald JM, Bishop JR, Smith RJ, Karniski LP \& Sheffield VC 2000 Functional differences of the PDS gene product are associated with phenotypic variation in patients with Pendred syndrome and non-syndromic hearing loss (DFNB4). Human Molecular Genetics 9 1709-1715.

Shafrir Y \& Guy HR 2004 STAM: simple transmembrane alignment method. Bioinformatics 20 758-769.

Sindic A, Chang MH, Mount DB \& Romero MF 2007 Renal physiology of SLC26 anion exchangers. Current Opinion in Nephrology and Hypertension 16 484-490.
Soleimani M \& Xu J 2006 SLC26 chloride/base exchangers in the kidney in health and disease. Seminars in Nephrology 26 375-385.

Soleimani M, Greeley T, Petrovic S, Wang Z, Amlal H, Kopp P \& Burnham CE 2001 Pendrin: an apical $\mathrm{Cl}^{-} / \mathrm{OH}^{-} / \mathrm{HCO}_{3}^{-}$exchanger in the kidney cortex. American Journal of Physiology. Renal Physiology 280 F356-F364.

Sweet RM \& Eisenberg D 1983 Correlation of sequence hydrophobicities measures similarity in three-dimensional protein structure. Journal of Molecular Biology 171 479-488.

Taylor JP, Metcalfe RA, Watson PF, Weetman AP \& Trembath RC 2002 Mutations of the PDS gene, encoding pendrin, are associated with protein mislocalization and loss of iodide efflux: implications for thyroid dysfunction in Pendred syndrome. Journal of Clinical Endocrinology and Metabolism 87 1778-1784.

Wall SM 2005 Recent advances in our understanding of intercalated cells. Current Opinion in Nephrology and Hypertension 14 480-484.

Wall SM 2006 The renal physiology of pendrin (SLC26A4) and its role in hypertension. Novartis Foundation Symposium 273 231-239.

Wall SM \& Pech V 2008 The interaction of pendrin and the epithelial sodium channel in blood pressure regulation. Current Opinion in Nephrology and Hypertension 17 18-24.

Wangemann P, Nakaya K, Wu T, Maganti RJ, Itza EM, Sanneman JD, Harbidge DG, Billings S \& Marcus DC 2007 Loss of cochlear $\mathrm{HCO}_{3}^{-}$ secretion causes deafness via endolymphatic acidification and inhibition of $\mathrm{Ca}^{2+}$ reabsorption in a Pendred syndrome mouse model. American Journal of Physiology. Renal Physiology 292 F1345-F1353.

Yang JJ, Tsai CC, Hsu HM, Shiao JY, Su CC \& Li SY 2005 Hearing loss associated with enlarged vestibular aqueduct and Mondini dysplasia is caused by splice-site mutation in the PDS gene. Hearing Research 199 22-30.

Yang T, Vidarsson H, Rodrigo-Blomqvist S, Rosengren SS, Enerback S \& Smith RJ 2007 Transcriptional control of SLC26A4 is involved in Pendred syndrome and nonsyndromic enlargement of vestibular aqueduct (DFNB4). American Journal of Human Genetics $\mathbf{8 0}$ $1055-1063$.

Yoon JS, Park HJ, Yoo SY, Namkung W, Jo MJ, Koo SK, Park HY, Lee WS, Kim KH \& Lee MG 2008 Heterogeneity in the processing defect of SLC26A4 mutants. Journal of Medical Genetics 45 411-419.

Yoshida A, Hattori K, Hisatome I, Taniguchi S, Ueta Y, Hukui H, Santo Y, Igawa O, Shigemasa C, Kosugi S et al. 1999 A TSH/dibutyryl cAMP activated $\mathrm{Cl}^{-} / \mathrm{I}^{-}$channel in FRTL-5 cells. Biochemical and Biophysical Research Communications 259 631-635.

Yoshida A, Taniguchi S, Hisatome I, Royaux IE, Green ED, Kohn LD \& Suzuki K 2002 Pendrin is an iodide-specific apical porter responsible for iodide efflux from thyroid cells. Journal of Clinical Endocrinology and Metabolism 87 3356-3361.

Yoshida A, Hisatome I, Taniguchi S, Sasaki N, YamamotoY, Miake J, Fukui H, Shimizu H, Okamura T, Okura T et al. 2004 Mechanism of iodide/chloride exchange by pendrin. Endocrinology 145 4301-4308.

Zhai Y \& Saier MH Jr 2001 A web-based program (WHAT) for the simultaneous prediction of hydropathy, amphipathicity, secondary structure and transmembrane topology for a single protein sequence. Journal of Molecular Microbiology and Biotechnology 3 501-502.

Received in final form 31 March 2009

Accepted 15 April 2009

Made available online as an Accepted Preprint 15 April 2009 